theory of magnetic storms ${ }^{2}$ proposed some years ago and by recent model experiments by Malmfors ${ }^{3}$, the electric field strength during a storm may be considerably greater, so that potential differences of some hundred megavolts, in exceptional cases still more, would be possible. But even the above value (50 MV.) is no doubt enough to affect the cosmic radiation appreciably. As the earth quickly attains about the potential of the stream, it would be negative in the beginning and positive at the end of a storm, resulting in an increase and later a decrease of cosmic radiation. This seems to be in general accord with what is observed.

Near other stars the same mechanism may give rise to still higher differences in potential. This is of interest with regard to the point of view ${ }^{4}$ according to which the cosmic radiation may be generated in electric fields produced by magnetic induction.

Department of Electronics,

Kungl. Tekniska Högskolan,

Valhallavägen,

Stockholm.

Sept. 28.

${ }^{1}$ Lange and Forbush, Terr. Mag., 47, 331 (1942).

'Alfvén, H., Kungl. Svenska Vet. Akad., Handlingar III, Bd. 18, No. 3 (1939); No. 9 (1940).

'Malmfors, K. G., Arkiv. för mat. astr. fysik., Bd. 34, B, No. 1 (1946).

-Alfvén, H., Z. Phys., 107, 579 (1937); Nature, 143, 435 (1939).

\section{Dielectric Dispersion in Crystalline Di-isopropyl Ketone}

DrPolar rotation is well known to occur in a number of organic crystals, for example, $d$-camphor ${ }^{1}$ and cyclopentanol ${ }^{2}$, and in ic $e^{3,4}$ far below the melting point. The dielectric behaviour of these substances is remarkable in that solidification is only shown as a minor discontinuity of the polarization curve, and it may be said that such compounds do not freeze dielectrically at their macroscopic freezing point. In some cases, dipolar rotation stops at a transition taking place at a lower temperature. Whether or not dispersion is observed in the crystalline state should depend on the frequency used.

It appears to be interesting that the dipolar rotation in crystalline di-isopropyl ketone, found in the course of another investigation, presents a different picture. Fig. 1 gives its dielectric constant $\varepsilon^{\prime}$ at two frequencies, and Fig. 2 the loss factor $\varepsilon^{\prime \prime}$ at three frequencies, measured by a resonance method, details of which have been given elsewhere ${ }^{5}$. The sample was fractionated under nitrogen, b.p. $+123^{\circ} \mathrm{C} ., n^{17} \cdot{ }^{5} D=$ 1.4107 , but it was found that its dielectric properties were little different from the untreated commercial product. The substance melts between $-72 \cdot 5^{\circ}$ and $-73 \cdot 5^{\circ} \mathrm{C}$. When approaching this point from higher temperatures, $\varepsilon^{\prime}$ and $\varepsilon^{\prime \prime}$ increase, the rise of $\varepsilon^{\prime \prime}$ indicating incipient anomalous dispersion. The liquid supercools generally to about $-80^{\circ}$, and crystallization is accompanied by a sharp drop of the dielectric constants; but $\varepsilon^{\prime}$ falls to a value appreciably higher than would be expected in a crystalline solid (that is, about $n^{2}$ ) and depends on the frequency. The reason for this frequency dependence is the occurrence of anomalous dispersion in the crystalline state shown by the peaks of $\varepsilon^{\prime \prime}$ in Fig. 2 and by the sigmoid shape of the $\varepsilon^{\prime}$-curves in Fig. 1. The dielectric constant $\varepsilon^{\prime}$ assumes its final value of about 2.4 on the low. temperature side of the dispersion range.

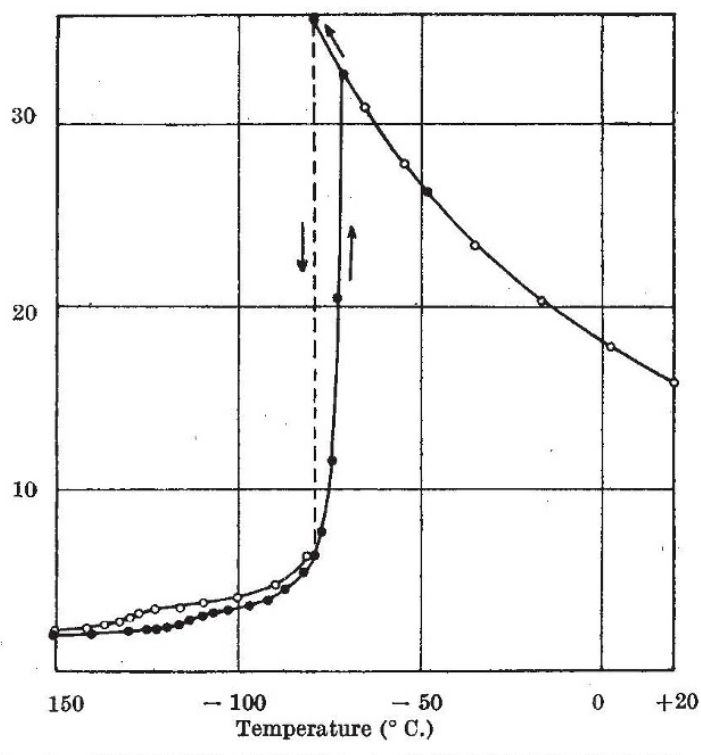

Fig. 1. DIELECTRIO CONSTANT, $\varepsilon^{\prime}$, OF DI-ISOPROPYI KETONE : —O-, at $1.12 \mathrm{Mc} . / \mathrm{s} . ;$ -

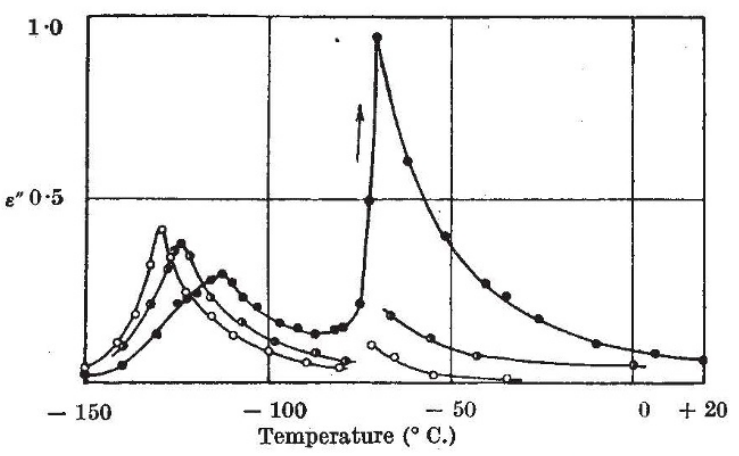

Fig. 2. LOSS FACTOR, $\varepsilon^{\prime \prime}$, OF DI-ISOPROPYL KETONE :

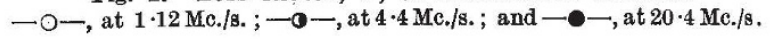

Measurements made at rising temperature give a gradual increase both of $\varepsilon^{\prime}$ and $\varepsilon^{\prime \prime}$ just below the melting point until the points coincide with those taken at falling temperature. Müller found this premelting effect on $\varepsilon^{\prime}$ in two straight ketones of higher molecular weight but no dispersion in the crystalline material.

In contradistinction to the substances mentioned above, the crystallization of di-isopropyl ketone has a profound influence on the polarization, and there is no sign of another transition below the melting point. It is tentatively suggested that branching of the molecule causes a crystal lattice somewhat looser than that of straight ketones and reduces the intra. molecular forces sufficiently to allow restricted molecular rotation.

\section{British Rubber Producers \\ Research Association, 48 Tewin Road,}

\section{A. Schallamach}

Welwyn Garden City, Herts. Sept. 30.

${ }^{1}$ White and Morgan, J. Amer. Chem. Soc., 57, 2079 (1935). White and Bishop, J. Amer. Chem. Soc., 62, 8 (1940). ${ }^{3}$ Smyth and Hitchcock, J. Amer. Chem. Soc., 54, 4631 (1932). ${ }^{4}$ Wintsch, Helv. Phys. Acta, 5, 126 (1932).

${ }^{5}$ Schallamach, Trans. Farad. Soc., 42, 495 (1946).

- Müller, Proc. Roy. Soc., A, 158, 403 (1937). 